\title{
Composição em ácidos graxos do leite de vacas alimentadas com glicerina de baixa pureza
}

\section{Fatty acid composition of milk from cows fed low purity glycerin}

\author{
Murilo de Almeida Meneses ${ }^{1 *}$; Fabiano Ferreira da Silva ${ }^{2}$; \\ Robério Rodrigues Silva²; Alex Resende Schio ; Gonçalo Mesquita da Silva"; \\ Eli Santana de Oliveira Rodrigues ${ }^{4}$; Antonio Ferraz Porto Junior ${ }^{5}$; \\ Dicastro Dias de Souza ${ }^{5}$; Wagner Patrick Sá Teles Silva Ponde ${ }^{6}$; \\ Julinessa Silva Oliveira de Oliveira ${ }^{4}$; Leidiane Reis Pimentel ${ }^{4}$
}

\section{Resumo}

Objetivou-se avaliar o efeito da inclusão de glicerina de baixa pureza na dieta sobre a composição em ácidos graxos do leite de vacas mestiças. Foram utilizadas 15 vacas mestiças Holandês x Zebu, distribuídas em três Quadrados Latinos 5 x 5, nos seguintes tratamentos: controle (sem inclusão de glicerina na dieta); inclusão de $5 \%$ de glicerina na matéria seca da dieta; inclusão de $10 \%$ de glicerina na matéria seca da dieta; inclusão de $15 \%$ de glicerina na matéria seca da dieta; e inclusão de $20 \%$ de glicerina na matéria seca da dieta. A inclusão de glicerina na dieta não afetou $(\mathrm{P}<0,05)$ a concentração do ácido butírico $(\mathrm{C} 4: 0)$. Em contrapartida, foi observado efeito quadrático $(\mathrm{P}<0,05)$ sobre as concentrações dos ácidos graxos caproíco $\mathrm{C}_{6: 0}$ (ponto de máxima $=11,33$ ), caprílico $\mathrm{C}_{8: 0}\left(\right.$ ponto de máxima $=9,50$ ) e cáprico $\mathrm{C}_{10: 0}$ (ponto de máxima $=6,66$ ) também ácidos graxos de cadeia curta, seguindo a mesma tendência da produção de leite. Houve efeito linear decrescente $(\mathrm{P}<0,05)$ sobre as concentrações dos ácidos graxos de cadeia média: os ácidos graxos Láurico $\mathrm{C}_{12: 0}$, Mirístico $\mathrm{C}_{14: 0}$, Miristoleico $\mathrm{C}_{14: 1}$, Pentadecanoico $\mathrm{C}_{15: 0}$, Pentadecenoico $\mathrm{C}_{15: 1}$, Palmítico $\mathrm{C}_{16: 0}$ e Palmitoleico $\mathrm{C}_{16: 1}$. Foi observado efeito linear crescente $(\mathrm{P}<0,05)$ sobre as concentrações dos ácidos graxos poli-insaturados e monoinsaturados. Em contrapartida, a concentração dos ácidos graxos saturados decresceu linearmente $(\mathrm{P}<0,05)$. A concentração dos ácidos graxos da série Omega 6 apresentou efeito linear decrescente $(\mathrm{P}<0,05)$. Não foi observado efeito da inclusão de glicerina sobre a concentração de Omega 3. A razão AGPI/AGS apresentou crescimento linear $(\mathrm{P}<0,05)$ e a razão n-6 n-3-1 apresentou efeito quadrático $(\mathrm{P}<0,05)$ com ponto de máxima de 8,35 . A concentração do ácido linoleico conjugado total apresentou efeito linear crescente $(\mathrm{P}<0,05)$. Recomenda-se a inclusão de glicerina na dieta de vacas leiteiras até o nível de $20 \%$ com base na matéria seca.

Palavras-chave: Ácidos graxos essenciais, biohidrogenação, CLA, razão ômega 6 e ômega 3

\section{Abstract}

This study aimed to evaluate the effect of inclusion of low purity glycerin in the diet on the fatty acid

\footnotetext{
${ }^{1}$ Discente de Doutorado em Zootecnia, Universidade Estadual do Sudoeste da Bahia, UESB, Bahia, BA. E-mail: dddmeneses@ msn.com

2 Pesquisadores, UESB, Itapetinga, BA. E-mail: ffsilvauesb@hotmail.com; rrsilva.uesb@hotmail.com

3 Pós-doutorando em Zootecnia, UESB, Itapetinga, BA. E-mail: resendezoo@hotmail.com

${ }^{4}$ Discentes de Doutorado em Zootecnia, UESB, Itapetinga, BA. E-mail: gon_zootecnia23@hotmail.com; eli.uesb@hotmail.com; julinessa1@hotmail.com; leidyrp@yahoo.com.br

5 Discentes de Mestrado em Zootecnia, UESB, Itapetinga, BA. E-mail: ferrazporto@hotmail.com; dico111_3@hotmail.com

${ }^{6}$ Zootecnista, Barreiras, BA. E-mail: patrickponde@hotmail.com

* Autor para correspondência
} 
composition of milk of crossbred cows. We used 15 crossbred Holstein $x$ Zebu cows distributed in three Latin squares $5 \times 5$, the following treatments: control (no addition of glycerin in the diet); inclusion of $5 \%$ glycerin in the diet dry matter; inclusion of $10 \%$ glycerol in the diet dry matter; inclusion of $15 \%$ glycerol in the diet dry matter, and the inclusion of $20 \%$ glycerol in the diet dry matter. The inclusion of glycerin in the diet had no effect $(\mathrm{P}<0.05)$ the concentration of butyric acid $(\mathrm{C} 4: 0)$. In contrast, we observed a quadratic effect $(\mathrm{P}<0.05)$ on the concentrations of fatty acids caproic $\mathrm{C}_{6: 0}(=11.33$ the point of maximum), caprylic $\mathrm{C}_{8: 0}\left(=9.50\right.$ the point of maximum) and capric $\mathrm{C}_{10: 0}(=6.66$ the point of maximum) also short chain fatty acids, following the same trend of milk production. Decreased linearly $(\mathrm{P}<0.05)$ concentrations of medium chain fatty acids, fatty acids Lauric $\mathrm{C}_{12: 0}$, Myristic $\mathrm{C}_{14: 0}$, myristoleic $\mathrm{C}_{14: 1}$, pentadecanoic $\mathrm{C}_{15: 0}$, Pentadecenoico: $\mathrm{C}_{15: 1}$, Palmitic C16:0 and palmitoleic $\mathrm{C}_{16: 1}$. Was observed increased linearly $(\mathrm{P}<0.05)$ on concentrations of polyunsaturated fatty acids and monounsaturated. In contrast, the concentration of saturated fatty acids decreased linearly $(\mathrm{P}<0.05)$. The concentration of fatty acids Omega 6 series showed decreasing linear effect $(\mathrm{P}<0.05)$. As for the concentration of Omega 3, there was no effect of adding glycerin. The PUFA SFA ${ }^{-1}$ ratio showed linear growth $(\mathrm{P}<0.05)$ and the ratio $n-6 n-3^{-1}$ showed a quadratic effect $(\mathrm{P}<0.05)$, with of 6.66 the point of maximum. The concentration of conjugated linoleic acid total had increased linearly $(\mathrm{P}<0.05)$. It is recommended the inclusion of glycerin in the diet of dairy cows to the level of $20 \%$ based on dry matter.

Key words: Essential fatty acids, biohydrogenation, CLA, omega 6 and omega 3 reason

\section{Introdução}

Não é recente a intenção de alterar a composição do leite, principalmente em relação à gordura. A perspectiva de manipular a gordura do leite visa atender à demanda de um mercado consumidor cada vez mais exigente em relação ao consumo de determinadas gorduras saturadas, em razão de seus efeitos deletérios sobre a saúde humana (EIFERT et al., 2006).

Uma das características do leite bovino é a grande proporção de ácidos graxos (AG) saturados, com cadeias de 4 a 16 carbonos, resultantes da síntese de novo. Alguns destes AG são apontados como precursores do colesterol sanguíneo de baixa densidade (LDL), responsável por doenças cardiovasculares (PARODI, 1999). Por isso, a tendência atual é a demanda crescente por alimentos saudáveis, com baixos teores de gordura saturada e, preferencialmente, com fatores que atuem na promoção de efeitos fisiológicos benéficos à saúde (PADILHA; PINHEIRO, 2004), como é o caso dos ácidos graxos de cadeia longa, mono e poliinsaturados, pois estes $A G$ possibilitam redução da incidência de doenças coronarianas, através do aumento do HDL, o colesterol de alta densidade.

Dentre os ácidos graxos insaturados, existe um que merece uma atenção especial, denominado ácido linoleico conjugado (CLA), comprovadamente anticarcinogênico, que previne contra doenças cardiovasculares (BAUMAN; GRIINARI, 2001).

Diante dessa nova realidade, surge a necessidade de investigar o perfil de ácidos graxos presentes na gordura do leite, bem como sua modificação. Uma vez que a quantidade e a composição em ácidos graxos da gordura do leite são os parâmetros passíveis de manipulação, podendo ser alterados por modificações do manejo alimentar dos animais, tais como o tipo de volumoso, relação volumoso: concentrado, a ingestão de fontes lipídicas, a fase da lactação, o balanço energético, o pH do rúmen, a biohidrogenação ruminal, dentre outros (CHILLIARD; BOCQUIER, 1993).

No entanto, a inclusão de lipídios na dieta provoca as maiores alterações na composição da gordura do leite, que são dependentes do nível e do tipo de lipídio e da extensão da bio-hidrogenação ruminal (GRUMMER, 1991).

A bio-hidrogenação ruminal deve-se à síntese do ácido linoleico conjugado, o CLA. Existem evidências de que esse ácido seria capaz de inibir o mecanismo que leva o organismo a acumular gordura e usar as reservas de gordura como fonte de 
energia. O CLA encontrado na gordura do leite e na carne de ruminantes apresenta duas origens: a biohidrogenação parcial do ácido linoleico no rúmen e a síntese endógena no tecido adiposo e na glândula mamária. A síntese endógena é mais importante do que a bio-hidrogenação ruminal na secreção de CLA, sendo responsável por cerca de $80 \%$ do CLA presente no leite (PALMQUIST; MATTOS, 2006).

A glicerina de baixa pureza é um coproduto da indústria do biodiesel, que vem sendo amplamente pesquisada na alimentação de ruminantes, devido ao seu valor energético que é similar ao do milho, o que gera grande interesse já que o milho entra em grandes proporções na dieta e a sua possível substituição por uma fonte alternativa pode interferir positivamente na rentabilidade do sistema produtivo.

O glicerol pode seguir duas rotas metabólicas no rúmen: a absorção direta pelo epitélio da parede ruminal; ou a transformação em ácidos graxos voláteis $(\mathrm{AGV})$ pelos microrganismos ruminais, resultando, principalmente, em ácido propiônico (BERGNER et al., 1995). Segundo Vasconcelos de Sá, Cammarota e Ferreira-Leitão (2014) após chegar ao fígado, via corrente sanguínea, tanto o glicerol como o propionato são transformados em glicose, por meio da gliconeogênese, o que faz dele um importante precursor desse carboidrato. Sendo assim, acredita-se que o uso de glicerol fornece maior aporte de glicose para o animal, com conseqüente redução da oxidação de ácidos graxos em períodos em que o consumo calórico é reduzido e as necessidades energéticas aumentadas. Objetivou-se com este trabalho avaliar a composição em ácidos graxos do leite de vacas recebendo níveis crescentes de glicerina de baixa pureza na dieta.

\section{Material e Métodos}

O experimento foi conduzido na fazenda Paulistinha, Macarani, BA. Foram utilizadas 15 vacas mestiças Holandês x Zebu (grau de sangue variando de $1 / 2$ a $3 / 4$ de sangue $H \times Z$ ), de terceira ou quarta ordem de lactação, com produção média ajustada para 300 dias nas lactações anteriores entre 3.000 e $4.000 \mathrm{~kg}$. As vacas foram selecionadas também para dias em lactação, entre 80 e 120 dias, no início do período experimental, sendo que cinco dessas vacas continham fístula ruminal. As 15 vacas lactantes foram distribuídas em três Quadrados Latinos 5 x 5, sendo os tratamentos descritos abaixo:

$0 \%=$ controle (sem inclusão de glicerina de baixa pureza na dieta);

$5 \%$ = inclusão de 5,00\% de glicerina de baixa pureza na matéria seca da dieta;

$10 \%$ = inclusão de $10,00 \%$ de glicerina de baixa pureza na matéria seca da dieta;

$15 \%$ = inclusão de $15,00 \%$ de glicerina de baixa pureza na matéria seca da dieta; e

$20 \%$ = inclusão de $20,00 \%$ de glicerina de baixa pureza na matéria seca da dieta.

O volumoso utilizado foi a cana-de-açúcar (Saccharum officinarum), variedade RB 72454, tratada com $1 \%$ da mistura de ureia e sulfato de amônia (9:1 parte), na fase experimental. Seguindo as recomendações de Santos et al. (2011), de um período de 7 dias antes do início do experimento, as vacas receberam o volumoso contendo apenas $0,5 \%$ da mistura de ureia, afim de se adaptarem a este constituinte adicionado ao volumoso, prevenindo, com isso, uma eventual intoxicação.

A relação volumoso:concentrado (Tabela 1) foi definida pelo balanceamento das dietas, a fim de conter nutrientes suficientes para mantença, ganho de peso corporal de $0,15 \mathrm{~kg} / \mathrm{dia}$ e produção de $15 \mathrm{~kg}$ de leite/dia, de acordo com o NRC (2001), utilizando como base, os dados da composição químico-bromatológica da cana-de-açúcar, milho, farelo de soja e glicerina de baixa pureza, realizada uma semana antes do período experimental.

Os animais foram alojados em baias individuais 
de $16 \mathrm{~m}^{2}$, cobertas, providas de cocho de concreto e bebedouro com capacidade de 200 litros, comum a duas baias, sendo abastecidos por gravidade. O alimento foi oferecido na forma de mistura completa, duas vezes ao dia, às $07 \mathrm{~h} 00 \mathrm{~min}$ e às $15 \mathrm{~h} 00 \mathrm{~min}$, à vontade, de modo a permitir $5 \%$ de sobras.

Tabela 1. Proporções de ingredientes nas rações experimentais com base na matéria seca.

\begin{tabular}{lccccc}
\hline \multirow{2}{*}{\multicolumn{1}{c}{ Alimentos (\%) }} & \multicolumn{5}{c}{ Níveis de Glicerina (\% MS) } \\
\cline { 2 - 5 } & $\mathbf{0}$ & $\mathbf{5}$ & $\mathbf{1 0}$ & $\mathbf{1 5}$ & $\mathbf{2 0}$ \\
\hline Cana-de-açúcar & 60,61 & 61,58 & 62,08 & 62,82 & 63,51 \\
Milho grão moído & 26,39 & 19,71 & 13,42 & 7,18 & 1,09 \\
Glicerina & 0,00 & 4,76 & 9,48 & 14,02 & 18,47 \\
Farelo de soja & 11,15 & 12,10 & 13,16 & 14,13 & 15,07 \\
Sal & 0,87 & 0,85 & 0,83 & 0,82 & 0,84 \\
Fosfato bicálcico & 0,59 & 0,65 & 0,68 & 0,74 & 0,77 \\
Calcário & 0,39 & 0,35 & 0,34 & 0,30 & 0,26 \\
\hline
\end{tabular}

${ }^{1}$ Composição: Cálcio 200 g; Cobalto 200 mg; Cobre 1.650 mg; Enxofre 12 g; Ferro 560 mg; Flúor (max) 1.000 ; Fósforo 100 g; Iodo 195 mg; Magnésio 15 g; Manganês 1.960 mg; Níquel 40 mg; Selênio 32 mg; Sódio 68 g; Zinco 6.285 mg.

Fonte: Elaboração dos autores.

O experimento iniciou-se no dia 19 de julho de 2011, sendo constituído de cinco períodos experimentais, com duração de 15 dias cada, sendo os primeiros 10 dias considerados de adaptação.
Em cada período experimental, foi realizada coleta do volumoso e dos suplementos para avaliação de sua composição químico-bromatológica (Tabela 2).

Tabela 2. Composição químico-bromatológica da cana e das dietas experimentais.

\begin{tabular}{lrrrrrr}
\hline \multirow{2}{*}{\multicolumn{1}{c}{ Componentes }} & Cana + & \multicolumn{5}{c}{ Nível de glicerina (\% MS) } \\
\cline { 5 - 7 } & Ureia & \multicolumn{1}{c}{$\mathbf{0}$} & $\mathbf{5}$ & $\mathbf{1 0}$ & $\mathbf{1 5}$ & $\mathbf{2 0}$ \\
\hline Matéria Seca (\%) & 30,05 & 52,74 & 50,95 & 50,11 & 48,88 & 47,79 \\
Matéria orgânica (\% da MS) & 96,58 & 94,83 & 93,73 & 93,82 & 93,71 & 93,47 \\
Proteína Bruta (\% da MS) & 13,26 & 15,21 & 15,22 & 15,39 & 15,50 & 15,95 \\
Extrato etéreo (\% da MS) & 1,20 & 2,09 & 3,08 & 4,38 & 5,92 & 7,01 \\
Fibra em detergente neutro ${ }_{\text {cp }}(\%$ da MS) & 50,62 & 38,87 & 38,44 & 37,60 & 38,08 & 37,44 \\
Fibra em detergente ácido (\% da MS) & 29,82 & 20,97 & 21,09 & 21,32 & 21,38 & 21,56 \\
Carboidratos não fibrosos (\% da MS) & 40,91 & 45,17 & 42,79 & 42,44 & 40,11 & 39,04 \\
Carboidratos totais (\% da MS) & 84,24 & 79,62 & 76,74 & 75,51 & 73,61 & 71,85 \\
Matéria mineral (\% da MS) & 3,42 & 5,17 & 6,27 & 6,18 & 6,29 & 6,53 \\
\hline
\end{tabular}

Fonte: Elaboração dos autores.

Também foram realizadas coletas da glicerina de baixa pureza adquirida na empresa Comanche Biocombustíveis da Bahia Ltda (Simões FilhoBA), em cada período experimental, para avaliação dos teores de metanol e glicerol, além de sua composição químico-bromatológica e de ácidos graxos (Tabelas 3 e 4 ).

Durante o período experimental, as variáveis 
ambientais de temperatura e precipitação pluviométrica (Tabela 5) foram registradas pela estação meteorológica instalada na Fazenda Paulistinha, localizada no município de MacaraniBA.

Do $11^{\circ}$ ao $15^{\circ}$ dia de cada período experimental, o alimento oferecido e as sobras foram pesados para determinar o consumo e amostrados para análises químico-bromatológicas. Ao final do período experimental, as amostras foram présecadas e moídas em moinho com peneira de $1 \mathrm{~mm}$, acondicionadas em vidro com tampa, previamente identificados, e armazenadas para posteriores análises, conforme Silva e Queiroz (2002).
Tabela 3. Composição química da glicerina.

\begin{tabular}{lc}
\hline Componente & Glicerina \\
\hline Metanol (\%) & 5,73 \\
Glicerol (\%) & 51,84 \\
Matéria seca (\%) & 90,00 \\
Matéria orgânica (\% da MS) & 93,00 \\
Proteína bruta (\% da MS) & 0,0001 \\
Lipídios (\% da MS) & 36,70 \\
\hline Ácido graxo & \\
\hline Saturados (\% dos lipídios) & 27,07 \\
Poli-insaturados (\% dos lipídios) & 47,93 \\
Monoinsaturados (\% dos lipídios) & 25,00 \\
\hline
\end{tabular}

Fonte: Elaboração dos autores.

Tabela 4. Percentual de lipídios e ácidos graxos na amostra de glicerina.

\begin{tabular}{|c|c|c|}
\hline 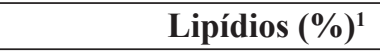 & 33,64 & 39,75 \\
\hline Ácido graxo $^{2}$ & Amostra $1(\%)$ & Amostra $2(\%)$ \\
\hline C14:0 & 0,83 & 0,80 \\
\hline C14:1 & 0,17 & 0,19 \\
\hline $\mathrm{C} 15$ & 0,02 & 0,04 \\
\hline $\mathrm{C} 16$ & 20,99 & 19,36 \\
\hline C16:1 & 1,19 & 1,78 \\
\hline $\mathrm{C} 17$ & 0,26 & 0,29 \\
\hline $\mathrm{C} 17: 1$ & 0,01 & 0,01 \\
\hline $\mathrm{C} 18$ & 5,50 & 4,74 \\
\hline C18:1T & 0,81 & 1,10 \\
\hline $\mathrm{C} 18: 1 \mathrm{C}$ & 21,92 & 22,65 \\
\hline C18:2N-6 & 45,12 & 46,26 \\
\hline C18:3N-6 & 0,30 & 0,34 \\
\hline C20:0 & 0,47 & 0,40 \\
\hline C18:3N-3 & 1,80 & 1,66 \\
\hline C20:1 & 0,09 & 0,08 \\
\hline $\mathrm{C} 20: 3 \mathrm{~N}-6$ & 0,03 & 0,04 \\
\hline $\mathrm{C} 22: 0$ & 0,18 & 0,17 \\
\hline $\mathrm{C} 24: 0$ & 0,05 & 0,05 \\
\hline Ácido graxo & Amostra $1(\%)$ & Amostra $2(\%)$ \\
\hline $\mathrm{AGS}^{3}$ & 28,30 & 25,85 \\
\hline $\mathrm{AGPI}^{4}$ & 47,24 & 48,30 \\
\hline $\mathrm{AGMI}^{5}$ & 24,19 & 25,81 \\
\hline AGPI/AGS ${ }^{6}$ & 1,67 & 1,87 \\
\hline
\end{tabular}

${ }^{1}$ Folch, Lees e Stanley (1957); ${ }^{2}$ método 5509 da ISO (1978); ácido Mirístico (C14:0); Miristoléico (C14:1), Pentadecanóico (C15:0); ácido palmitíco (C16); ácido palmitoléico (16:1); ácido margárico (C17:0) ácido heptadecanóico (C17:1); ácido esteárico (C18:0), ácido oléico (C18:1n9); ácido linoleico (C18:2), linolênico (C18:3) ácido araquidíco (C20:0) e ácido behênico (C22:0), ${ }^{3}$ ácidos graxos saturados, ${ }^{4}$ ácidos graxos poli-insaturados, ${ }^{5}$ ácidos graxos monoinsaturados, 6 relação entre ácidos graxos poli-insaturados e saturados. Fonte: Elaboração dos autores. 
Tabela 5. Temperatura média, médias das temperaturas máximas (TMAX) e mínimas (TMIN) e precipitação pluviométrica total, por mês, observadas durante a fase experimental.

\begin{tabular}{lccc}
\hline \multirow{2}{*}{ Item } & \multicolumn{3}{c}{ Mês } \\
\cline { 2 - 4 } & Julho & Agosto & Setembro \\
\hline TMAX $\left(\mathrm{C}^{\circ}\right)$ & 28,38 & 31,42 & 33,60 \\
TMIN $\left(\mathrm{C}^{\circ}\right)$ & 18,05 & 17,51 & 16,38 \\
Média $\left(\mathrm{C}^{\circ}\right)$ & 23,65 & 26,01 & 25,88 \\
Precipitação $(\mathrm{mm})$ & 19,7 & 3,0 & 3,9 \\
\hline
\end{tabular}

Fonte: Elaboração dos autores.

Amostras de leite das ordenhas do $12^{\circ}$ dia foram coletadas na quantidade de $1 \%$ da produção de cada animal para determinação de proteína, conforme descrito por Silva e Queiroz (2002); e de gordura, lactose e sólidos totais, conforme descrito por Pregnolato e Pregnolato (1985). A composição química do leite está apresentada na tabela 6 .

Tabela 6. Composição do leite de vacas lactantes alimentadas com diferentes níveis de glicerina na dieta.

\begin{tabular}{lccccc}
\hline \multirow{2}{*}{ Composição } & \multicolumn{5}{c}{ Nível de glicerina (\% MS) } \\
\cline { 2 - 5 } & $\mathbf{0}$ & $\mathbf{5}$ & $\mathbf{1 0}$ & $\mathbf{1 5}$ & $\mathbf{2 0}$ \\
\hline Proteína & 2,81 & 2,90 & 2,77 & 2,69 & 2,74 \\
Gordura & 3,52 & 3,44 & 3,35 & 3,30 & 3,25 \\
Lactose & 4,23 & 4,36 & 4,18 & 4,04 & 4,12 \\
Minerais & 0,63 & 0,65 & 0,62 & 0,60 & 0,61 \\
Sólidos desengordurados & 7,70 & 7,94 & 7,61 & 7,35 & 7,51 \\
Sólidos totais & 11,19 & 11,35 & 10,92 & 10,63 & 10,72 \\
\hline
\end{tabular}

Fonte: Elaboração dos autores.

Foram coletadas amostras de $100 \mathrm{~mL}$ de leite da produção diária e congeladas para posterior análise da composição em ácidos graxos do leite.

Para a extração dos lipídios totais do leite in natura, $50 \mathrm{~mL}$ de cada amostra descongelada foram centrifugados a $12.000 \mathrm{rpm}$ por $30 \mathrm{~min}$, a $4^{\circ} \mathrm{C}$, em Micro-Centrífuga de Alta Rotação Himac CF-16RX II. A camada sólida formada na parte superior foi coletada e armazenada em frascos eppendorfs para posterior análise (REVENEAU, 2008).

Os lipídios extraídos do leite in natura foram submetidos à preparação de ésteres metílicos de ácidos graxos, conforme procedimento descrito por Bannon et al. (1982), com modificações descritas por Simionato et al. (2010).

Foram adicionados $5 \mathrm{~mL}$ de solução de metóxido de sódio $0,25 \mathrm{~mol} \mathrm{~L}^{-1}$ em metanol-dietil éter (1:1), em um tubo de tampa rosqueável, com aproximadamente $150 \mathrm{mg}$ de lipídios, agitando por 3 minutos. À mistura, foram adicionados 2 $\mathrm{mL}$ de iso-octano e $10 \mathrm{~mL}$ de solução saturada de cloreto de sódio. O tubo foi novamente agitado e deixado em repouso para separação das fases, o sobrenadante foi transferido para frascos eppendorf, devidamente identificados, para posterior análise cromatográfica. 
Os ésteres de ácidos graxos foram analisados por cromatógrafo a gás Thermo Finnigan, modelo Trace-GC-Ultra, equipado com Detector de Ionização de Chama (DIC) e coluna capilar de sílica fundida BPX-70 (120m, 0,25mm d.i). As vazões dos gases (White Martins) foram de $6,5 \mathrm{~mL} \mathrm{~min}^{-1}$ para o gás de arraste $(\mathrm{H} 2) ; 30 \mathrm{~mL} \mathrm{~min}^{-1}$ para o gás auxiliar (N2); $30 \mathrm{~mL} \mathrm{~min}^{-1}$ para o $\mathrm{H} 2$ e $250 \mathrm{~mL} \mathrm{~min}^{-1}$ para o ar sintético da chama. A razão da divisão da amostra foi de 90:10.

Os parâmetros de funcionamento foram estabelecidos após verificação da condição de melhor resolução. As temperaturas do injetor e detector foram de $250^{\circ} \mathrm{C}$ e $280^{\circ} \mathrm{C}$, respectivamente. A temperatura da coluna foi programada a $140^{\circ} \mathrm{C}$, por 10 minutos, seguido por uma primeira fase de $15^{\circ} \mathrm{C} \mathrm{m^{-1 }}$ até atingir $200^{\circ} \mathrm{C}$, permanecendo por 1 minuto. A segunda fase foi de $10^{\circ} \mathrm{C} \mathrm{min}^{-1}$ até atingir $230^{\circ} \mathrm{C}$, permanecendo 1 minuto nesta temperatura. A terceira fase de $0,4^{\circ} \mathrm{C} \mathrm{min}-1$ até atingir $233^{\circ} \mathrm{C}$ por 3 minutos. A última fase foi de $0,5^{\circ} \mathrm{C} \mathrm{min}^{-1}$ até atingir $238^{\circ} \mathrm{C}$ por 2 minutos. $\mathrm{O}$ tempo total de análise foi de 41,50 minutos.

As injeções foram realizadas em duplicata e os volumes das injeções foram de 1,2 $\mu \mathrm{L}$. As áreas dos picos dos ésteres metílicos de ácidos graxos foram determinadas através do software ChromQuest 4.1.

A identificação dos ácidos graxos foi realizada após verificação do comprimento equivalente de cadeia (ECL - Equivalent Lengthof Chain) dos picos e comparação dos tempos de retenção de padrões de ésteres metílicos de ácidos graxos contendo os isômeros c9t11 e t10c12 do ácido linoleico (189-
19, O-5632 e O-5626, Sigma, EUA). Os valores do ECL foram determinados conforme proposto por Visentainer e Franco (2006).

Os dados foram submetidos à análise de variância e regressão, utilizando-se o sistema de análise estatística e genética (SAEG, 2007), adotando-se o teste $\mathrm{F}$ a $5 \%$ de probabilidade.

\section{Resultados e Discussão}

Não foi observado efeito $(\mathrm{P}>0,05)$ da inclusão de glicerina de baixa pureza sobre a concentração do ácido graxo butírico $\mathrm{C}_{4: 0}$, apresentando média de 2,86 (Tabela 7). Segundo Davis e Collier (1985), os ácidos graxos de cadeia curta são originados na síntese de novo, na qual ocorre uma intensa atividade lipogênica a partir do acetato e $\beta$-hidroxibutirato, que são originados no rúmen. A principal via metabólica da síntese de novo envolve duas enzimas lipogênicas: acetil-CoA carboxilase e ácido graxo sintetase. A primeira é responsável pela formação do malonil-CoA, a partir do acetato, e a segunda catalisa a condensação do malonil-CoA com acetil-CoA ou butiril-CoA, produzidos a partir do metabolismo do acetato e $\beta$-hidroxibutirato, respectivamente (CHILLIARD et al., 2000).

$\mathrm{O}$ ácido graxo butírico (C4:0) foi o único $\mathrm{AG}$ que não foi afetado $(\mathrm{P}>0,05)$ pela inclusão de glicerina de baixa pureza, provavelmente, devido sua síntese ocorrer após o $\beta$-hidroxibutirato sofrer $\beta$-redução, não dependendo da participação de malonil-CoA ou da ação da acetilCoA carboxilase (FOX; MCSWEENEY, 1998). 
Tabela 7. Composição em ácidos graxos de cadeias curtas do leite de vacas alimentadas com diferentes níveis de glicerina na dieta.

\begin{tabular}{lcccccccc}
\hline \multirow{2}{*}{ Ácidos Graxos } & \multicolumn{9}{c}{ Nível de glicerina (\% MS) } & \multirow{2}{*}{ Eq. $^{\mathbf{1}}$} & \multirow{2}{*}{$\mathbf{C V}^{\mathbf{2}}$} & \multirow{2}{*}{$\mathbf{P}^{\mathbf{3}}$} \\
\cline { 2 - 6 } & $\mathbf{0}$ & $\mathbf{5}$ & $\mathbf{1 0}$ & $\mathbf{1 5}$ & $\mathbf{2 0}$ & & & \\
\hline $\mathrm{C}_{4: 0}$ & 2,61 & 2,92 & 3,07 & 2,93 & 2,75 & 4 & 12,44 & 0,063 \\
$\mathrm{C}_{6: 0}$ & 2,60 & 2,83 & 2,92 & 2,76 & 2,42 & 5 & 12,97 & 0,031 \\
$\mathrm{C}_{8: 0}$ & 1,88 & 2,06 & 2,12 & 1,97 & 1,67 & 6 & 12,64 & 0,002 \\
$\mathrm{C}_{10: 0}$ & 4,76 & 4,91 & 4,91 & 4,39 & 3,57 & 7 & 13,07 & 0,001 \\
\hline
\end{tabular}

${ }^{1}$ Equações de regressão; ${ }^{2}$ Coeficiente de variação em porcentagem; ${ }^{3}$ Probabilidade de erro; ${ }^{4} \mathrm{Y}=2,86 ;{ }^{5} \mathrm{Y}=2,600+0,068 \mathrm{x}-0,003 \mathrm{x}^{2}$, $\mathrm{R}^{2}=0,99$,Ponto de máximo $=11,33 ;{ }^{6} \mathrm{Y}=1,874+0,057 \mathrm{x}-0,003 \mathrm{x}^{2}, \mathrm{R}^{2}=1,00$,Ponto de máximo $=9,5 ;{ }^{7} \mathrm{Y}=4,738+0,080 \mathrm{x}-0,006 \mathrm{x}^{2}$, $\mathrm{R}^{2}=0,99$,Ponto de máximo $=6,66$.

Fonte: Elaboração dos autores.

As concentrações dos ácidos graxos caproíco $\mathrm{C}_{6: 0}$, caprílico $\mathrm{C}_{8: 0}$ e cáprico $\mathrm{C}_{10: 0}$ apresentaram efeito quadrático $(\mathrm{P}<0,05)$, com pontos de máxima de 11,$33 ; 9,50$ e 6,66, respectivamente, com a inclusão dos níveis de glicerina. Este efeito pode ser explicado pelo mesmo efeito observado para a produção de leite, pois seguiu a mesma tendência quadrática com a inclusão dos níveis de glicerina. Esta variação, provavelmente, ocorreu em função dos ácidos graxos poli-insaturados presentes na composição da glicerina de baixa pureza, ter provocado variação na relação acetato: propionato, devido à fermentação do glicerol em maiores teores de propionato no rúmen. Segundo Piperova, Teter e Bruckental (2000), os ácidos graxos poli-insaturados presentes na glicerina inibem a ação das enzimas lipogênicas acetil-coa carboxilase e ácido graxo sintetase, através da menor proporção de acetato no rúmen, onde essas enzimas são responsáveis pela síntese de novo de lipídios na glândula mamária, determinando a formação dos ácidos graxos de cadeias curtas e médias (de 4 a 16 carbonos) secretados no leite. Segundo os mesmos autores, este efeito pode causar mudança no perfil de ácidos graxos de cadeia curta e reduzir o teor de gordura do leite, como observado no presente estudo.

Houve efeito linear decrescente $(\mathrm{P}<0,05)$ para as concentrações dos ácidos graxos (Tabela 8) de cadeia média, Os ácidos graxos Láurico $\mathrm{C}_{12: 0}$, Mirístico $\mathrm{C}_{14: 0}$, Miristoleico $\mathrm{C}_{14: 1}$, Pentadecanoico $\mathrm{C}_{15: 0}$, Pentadecenoico $\mathrm{C}_{15: 1}$, Palmítico $\mathrm{C}_{16: 0}$ e Palmitoleico $\mathrm{C}_{16: 1}$, apresentaram decréscimo de 0,098; 0,218; 0,$015 ; 0,034 ; 0,003 ; 0,542$ e 0,016 , respectivamente, para cada unidade de glicerina inclusa.

Tabela 8. Composição em ácidos graxos de cadeias médias do leite de vacas lactantes alimentadas com diferentes níveis de glicerina na dieta.

\begin{tabular}{|c|c|c|c|c|c|c|c|c|}
\hline \multirow{2}{*}{ Ácidos Graxos } & \multicolumn{5}{|c|}{ Nível de glicerina (\% MS) } & \multirow{2}{*}{ Eq. ${ }^{1}$} & \multirow{2}{*}{$\mathrm{CV} \%{ }^{2}$} & \multirow{2}{*}{$\mathbf{P}^{3}$} \\
\hline & 0 & 5 & 10 & 15 & 20 & & & \\
\hline $\mathrm{C}_{12: 0}$ & 6,03 & 5,71 & 5,54 & 4,87 & 3,99 & 4 & 11,95 & 0,001 \\
\hline $\mathrm{C}_{14: 0}^{12: 0}$ & 15,34 & 14,33 & 13,97 & 12,34 & 10,87 & 5 & 8,46 & 0,001 \\
\hline $\mathrm{C}_{14: 1}^{140}$ & 1,43 & 1,18 & 1,29 & 1,10 & 1,08 & 6 & 17,95 & 0,006 \\
\hline $\mathrm{C}_{15: 0}^{14.1}$ & 1,95 & 1,54 & 1,51 & 1,30 & 1,23 & 7 & 16,90 & 0,001 \\
\hline $\mathrm{C}_{15: 1}$ & 0,11 & 0,15 & 0,10 & 0,09 & 0,09 & 8 & 19,34 & 0,001 \\
\hline $\mathrm{C}_{16: 0}^{15,1}$ & 34,74 & 28,57 & 26,52 & 23,70 & 23,61 & 9 & 9,00 & 0,001 \\
\hline $\mathrm{C}_{16: 1}^{10.0}$ & 1,66 & 1,38 & 1,27 & 1,18 & 1,34 & 10 & 21,65 & 0,016 \\
\hline
\end{tabular}

${ }^{1}$ Equações de regressão; ${ }^{2}$ Coeficiente de variação em porcentagem; ${ }^{3}$ Probabilidade de erro; ${ }^{4} \mathrm{Y}=6,21-0,098 \mathrm{x}, \mathrm{R}^{2}=0,92 ;{ }^{5} \mathrm{Y}=15,55$ $0,218 \mathrm{x}, \mathrm{R}^{2}=0,96 ;{ }^{6} \mathrm{Y}=1,372-0,015 \mathrm{x}, \mathrm{R}^{2}=0,72 ;{ }^{7} \mathrm{Y}=1,854-0,034 \mathrm{x}, \mathrm{R}^{2}=0,89 ;{ }^{8} \mathrm{Y}=0,152-0,003 \mathrm{x}, \mathrm{R}^{2}=0,36 ;{ }^{9} \mathrm{Y}=32,85-0,542 \mathrm{x}, \mathrm{R}^{2}$ $=0,88 ;{ }^{10} \mathrm{Y}=1,534-0,016 \mathrm{x}, \mathrm{R}^{2}=0,54$.

Fonte: Elaboração dos autores. 
Este efeito era esperado, uma vez que a modificação da composição em ácidos graxos de cadeias curta e média está associada à redução do teor de gordura do leite (AVILA; De PETERS; PEREZ-MONTI, 2000), fato este que foi observado na composição do leite no presente estudo. Isso está associado à menor presença de ácidos graxos saturados (AGS) e maior de ácidos graxos poliinsaturados (AGPI) na composição da glicerina de baixa pureza inserida em níveis crescentes na dieta e a ação inibidora desses AGPI sobre as enzimas responsáveis pela síntese dos AGS na glândula mamária. Santos et al. (2001), avaliando a inclusão de soja integral moída e óleo de soja nas dietas de vacas leiteiras, observaram redução dos ácidos graxos láurico, mirístico e palmítico.

Do ponto de vista nutricional, essa redução observada de ácidos láurico, mirístico e palmítico, neste trabalho, é considerada desejável, uma vez que esses ácidos induzem o aumento de colesterol no sangue, sendo associado às doenças cardiovasculares (COSTA et al., 2008).
A concentração do margárico $C_{17: 0}$ foi afetada pela inclusão de glicerina $(\mathrm{P}<0,05)$, decrescendo linearmente em 0,004 para cada unidade de glicerina adicionada (Tabela 9). O teor do ácido graxo saturado $\left(\mathrm{C}_{\text {17:0 }}\right)$ no leite resulta de quantidades extraídas do sangue, provenientes da síntese bacteriana no rúmen (MASSART-LËEN et al., 1983). A importância da capacidade de extração de nutrientes da corrente sanguínea para a síntese dos componentes do leite, de acordo com Madsen, Nielsen e Nielsen (2004), está positivamente correlacionada com a extração de triglicerídeos pela glândula mamária e que a limitação era decorrente da reduzida capacidade de síntese desta glândula, embora eles tenham verificado também que a limitação da retenção de acetato e $\beta$-hidroxibutirato tinha sido decorrente, principalmente, do fornecimento arterial desses metabólitos. Demeyer e Doreau (1999) afirmaram que, em altas quantidades de lipídios dietéticos, bactérias e protozoários podem incorporar o ácido linoleico e outros AG em sua estrutura de membrana, inibindo a síntese de novo microbiana, o que justifica a menor proporção de ácidos de cadeia ímpar nas dietas contendo glicerina.

Tabela 9. Composição em ácidos graxos de cadeias longas do leite de vacas lactantes alimentadas com diferentes níveis de glicerina na dieta.

\begin{tabular}{|c|c|c|c|c|c|c|c|c|}
\hline \multirow{2}{*}{ Ácidos Graxos } & \multicolumn{5}{|c|}{ Nível de glicerina (\% MS) } & \multirow{2}{*}{ Eq. ${ }^{1}$} & \multirow{2}{*}{ CV\% ${ }^{2}$} & \multirow{2}{*}{$\mathbf{P}^{3}$} \\
\hline & $\mathbf{0}$ & 5 & 10 & 15 & 20 & & & \\
\hline $\mathrm{C}_{17: 0}$ & 0,52 & 0,49 & 0,43 & 0,43 & 0,44 & 4 & 11,93 & 0,002 \\
\hline $\mathrm{C}_{17: 1}$ & 0,28 & 0,25 & 0,21 & 0,24 & 0,27 & 5 & 19,70 & 0,124 \\
\hline $\mathrm{C}_{18: 0}$ & 6,52 & 9,29 & 10,41 & 12,17 & 12,50 & 6 & 12,58 & 0,001 \\
\hline $\mathrm{C}_{18: \ln 7}$ & 1,07 & 1,79 & 2,56 & 4,10 & 5,38 & 7 & 39,24 & 0,001 \\
\hline $\mathrm{C}_{18: \ln 9}$ & 14,57 & 17,98 & 18,70 & 21,80 & 24,97 & 8 & 13,11 & 0,001 \\
\hline $\mathrm{C}_{18: 2 \mathrm{n} 6}$ & 1,66 & 1,81 & 1,59 & 1,51 & 1,37 & 9 & 15,04 & 0,003 \\
\hline $\mathrm{C}_{18: 2 \text { cis-9 } 9 \text { trans-11 }}$ & 0,42 & 0,66 & 1,28 & 1,39 & 2,05 & 10 & 34,36 & 0,001 \\
\hline $\mathrm{C}_{18: 2 \text { trans-10 cis- } 12}$ & 0,16 & 0,19 & 0,21 & 0,36 & 0,33 & 11 & 24,65 & 0,001 \\
\hline $\mathrm{C}_{18: 3 \mathrm{n}-3}$ & 0,14 & 0,18 & 0,15 & 0,15 & 0,15 & 12 & 21,07 & 0,058 \\
\hline $\mathrm{C}_{20: 0}$ & 0,12 & 0,15 & 0,13 & 0,15 & 0,16 & 13 & 14,70 & 0,001 \\
\hline $\mathrm{C}_{22: 0}$ & 0,05 & 0,10 & 0,08 & 0,09 & 0,09 & 14 & 24,01 & 0,001 \\
\hline
\end{tabular}

${ }^{1}$ Equações de regressão; ${ }^{2}$ Coeficiente de variação em porcentagem; ${ }^{3}$ Probabilidade de erro; ${ }^{4} \mathrm{Y}=0,504-0,004 \mathrm{x}, \mathrm{R}^{2}=0,63 ;{ }^{5} \mathrm{Y}=0,25$; ${ }^{6} \mathrm{Y}=7,22+0,296 \mathrm{x}, \mathrm{R}^{2}=0,93 ;{ }^{7} \mathrm{Y}=0,792+0,219 \mathrm{x}, \mathrm{R}^{2}=0,98 ;{ }^{8} \mathrm{Y}=14,68+0,492 \mathrm{x}, \mathrm{R} 2=0,97 ;{ }^{9} \mathrm{Y}=1,762-0,017 \mathrm{x}, \mathrm{R}^{2}=0,72 ;{ }^{10} \mathrm{Y}=$ $0,368+0,079 \mathrm{x}, \mathrm{R}^{2}=0,96 ;{ }^{11} \mathrm{Y}=0,154+0,009 \mathrm{x}, \mathrm{R}^{2}=0,79 ;{ }^{12} \mathrm{Y}=0,154 ;{ }^{13} \mathrm{Y}=0,124+0,002 \mathrm{x}, \mathrm{R}^{2}=0,62 ;{ }^{14} \mathrm{Y}=0,063+0,001 \mathrm{x}, \mathrm{R}^{2}=0,86$. Fonte: Elaboração dos autores. 
Para o heptadenoico $\mathrm{C}_{17: 1}$, a inclusão de glicerina não influenciou a concentração deste ácido graxo $(\mathrm{P}>0,05)$ com média de 0,25 . Para as concentrações

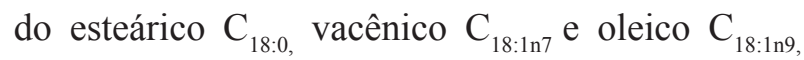
observou-se efeito linear crescente $(P<0,05)$, com acréscimo de 0,296; 0,219 e 0,492, respectivamente, para cada unidade de glicerina de baixa pureza inclusa. Este acréscimo pode ser explicado pelas concentrações dos mesmos na composição da glicerina, pois aumentaram linearmente, à medida que a glicerina foi inclusa.

Segundo Berchielli, Pires e Oliveira (2006), a enzima $\Delta-9$ dessaturase tem papel importante na modificação da composição dos ácidos graxos da gordura do leite, sendo responsável também por converter ácidos esteárico (C18:0) em ácidos oleico (C18:1cis 9), o ácido vacênico (C18:1 trans 11) em ácido rumênico (CLA), (C18:2 cis 9 trans 11). Observa-se que 60 a $95 \%$ do CLA, encontrado na gordura do leite, são originados pela ação dessa enzima (BERCHIELLI; PIRES; OLIVEIRA, 2006).

Malau-Aduli, Siebert e Bottema (1997) e Beaulieu, Drackley e Merchen (2002) destacaram que a atividade das enzimas $\Delta-9$ dessaturase pode ser alterada por diversos fatores como raça, idade, sexo e grau de maturidade fisiológica dos animais. Parte do ácido esteárico é transformada em ácido oleico pela ação da enzima $\Delta-9$ dessaturase na glândula mamária, e essa, por sua vez, promove a insaturação do ácido esteárico (18:0) no carbono 9, originando o ácido oleico (18:1n-9) (FERNANDES et al., 2009). O AG esteárico (18:0) aumentou com o aumento dos níveis de glicerina de baixa pureza na dieta, e consequentemente, foi observado o mesmo comportamento para o ácido oleico (18:1n-9).

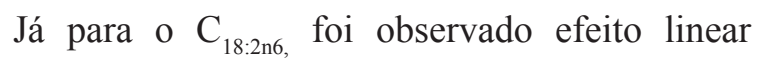
decrescente $(\mathrm{P}<0,05)$, com redução de 0,017 para cada unidade de glicerina adicionada na dieta. Este efeito pode ser justificado pelo processo de bio-hidrogenação do ácido linoleico que, em consequência, aumenta as concentrações dos seus isômeros principais $\mathrm{C}_{18: 2}$ cis-9 trans-11 e $\mathrm{C}_{18: 2}$ trans-10 cis-12, como foi observado no presente estudo.

As concentrações dos ácidos linoleico conjugado (CLA) $\mathrm{C}_{18: 2}$ cis-9 trans-11 e $\mathrm{C}_{18: 2}$ trans-10 cis-12 apresentaram efeito linear crescente $(\mathrm{P}<0,05)$, com acréscimo de 0,079 e 0,009 , respectivamente, para cada unidade de glicerina de baixa pureza acrescentada. Os maiores valores de CLA encontrados podem ser explicados, provavelmente, pela maior disponibilidade de ácidos graxos insaturados para bio-hidrogenação ruminal e da ação de dessaturação do ácido vaccênico pela enzima $\Delta 9$-dessaturase na glândula mamária.

Segundo Oliveira, Reis e Ladeira (2007), a concentração de CLA nos produtos derivados dos ruminantes depende de dois processos: a biohidrogenação ruminal e a dessaturação endógena do ácido vaccênico pela $\Delta 9$-dessaturase nos tecidos, em que a dieta é o principal fator que influencia os teores de CLA. Mcguire et al. (1996) obtiveram aumento linear na concentração de CLA no leite, alcançando um índice de 300\%, ao variar o nível de lipídios insaturados na dieta de 3 a 7,2\%, utilizando o óleo de milho. Santos et al. (2001), testando soja integral moída e óleo de soja, afirmaram que a ração suplementada com óleo de soja aumentou significativamente o percentual de CLA, comparada à ração com grão de soja, e justificou devido ao fato de os ácidos linoleico e linolênico estarem mais disponíveis para ser biohidrogenados e, assim, formarem o CLA durante a fase de isomerização. Resultados semelhantes foram encontrados nesta pesquisa.

Para o $\mathrm{C}_{18: 3 n-3}$, a inclusão de glicerina na dieta não afetou os tratamentos, apresentando média de 0,154 . Provavelmente, devido à pequena quantidade do mesmo presente na composição da glicerina de baixa pureza, não diferindo, assim, entre os tratamentos.

Para as concentrações dos ácidos graxos araquídico $\mathrm{C}_{20: 0}$ e behênico $\mathrm{C}_{22: 0 \text {, também foi }}$ 
observado efeito linear crescente $(\mathrm{P}<0,05)$, com acréscimo de 0,002 e 0,001 para cada unidade de glicerina inclusa. A redução nas concentrações de $\mathrm{C}_{18: 2 n 6}$ pode justificar o acréscimo, uma vez que os ácidos graxos $\mathrm{C}_{18: 3}$ e $\mathrm{C}_{18: 2}$ são responsáveis pela síntese, alongamento e dessaturação, através do $\Delta-6$ dessaturase do AG araquidíco (C20) e dos ácidos graxos que apresentam mais de 22 carbonos em sua estrutura (PALMQUIST; MATTOS, 2006).
Foi observado efeito linear crescente $(\mathrm{P}<0,05)$ nas concentrações dos AGPI e ácidos graxos monoinsaturados (AGMI), com acréscimo de 0,070 e 0,676, respectivamente, para cada unidade de glicerina adicionada (Tabela 10). Este efeito pode ser justificado pela maior proporção destes ácidos graxos presentes na glicerina de baixa pureza, na qual parte destes AGPI escapa do processo de biohidrogenação ruminal e é absorvido pelo intestino delgado, elevando, assim, seus teores no leite.

Tabela 10. Composição em ácidos graxos do leite de vacas lactantes alimentadas com diferentes níveis de glicerina na dieta.

\begin{tabular}{|c|c|c|c|c|c|c|c|c|}
\hline \multirow{2}{*}{ Ácidos Graxos } & \multicolumn{5}{|c|}{ Nível de glicerina (\% MS) } & \multirow[b]{2}{*}{ Eq. ${ }^{1}$} & \multirow[b]{2}{*}{ CV\%2 } & \multirow[b]{2}{*}{$\mathbf{P}^{3}$} \\
\hline & $\mathbf{0}$ & 5 & 10 & 15 & 20 & & & \\
\hline AGPI $^{12}$ & 2,68 & 3,17 & 3,48 & 3,66 & 4,19 & 4 & 15,08 & 0,001 \\
\hline $\mathrm{AGMI}^{13}$ & 19,12 & 22,74 & 24,15 & 28,52 & 33,15 & 5 & 10,86 & 0,001 \\
\hline $\mathrm{AGS}^{14}$ & 77,52 & 73,28 & 71,98 & 67,46 & 63,68 & 6 & 4,96 & 0,001 \\
\hline$n-6^{15}$ & 1,79 & 2,01 & 1,73 & 1,64 & 1,53 & 7 & 13,65 & 0,001 \\
\hline$n-3^{16}$ & 0,29 & 0,30 & 0,25 & 0,26 & 0,28 & 8 & 12,95 & 0,112 \\
\hline AGPI/AGS ${ }^{17}$ & 0,034 & 0,043 & 0,048 & 0,054 & 0,066 & 9 & 21,03 & 0,001 \\
\hline$n-6 / n-3^{18}$ & 6,28 & 6,84 & 7,01 & 6,39 & 5,56 & 10 & 15,84 & 0,028 \\
\hline CLA $^{19}$ & 0,59 & 0,85 & 1,50 & 1,75 & 2,37 & 11 & 29,38 & 0,001 \\
\hline
\end{tabular}

${ }^{1}$ Equações de regressão; ${ }^{2}$ Coeficiente de variação em porcentagem; ${ }^{3}$ Probabilidade de erro; ${ }^{4} \mathrm{Y}=2,732+0,070 \mathrm{x}, \mathrm{R}^{2}=0,97 ;{ }^{5} \mathrm{Y}=$ $18,76+0,676 \mathrm{x}, \mathrm{R}^{2}=0,97 ;{ }^{6} \mathrm{Y}=77,48-0,669 \mathrm{x}, \mathrm{R}^{2}=0,98 ;{ }^{7} \mathrm{Y}=1,906-0,014 \mathrm{x}, \mathrm{R} 2=0,61 ;{ }^{8} \mathrm{Y}=0,28 ;{ }^{9} \mathrm{Y}=0,034+0,001 \mathrm{x}, \mathrm{R}^{2}=0,98$; ${ }^{10} \mathrm{Y}=6,282+0,167 \mathrm{x}-0,010 \mathrm{x}^{2}, \mathrm{R} 2=0,99$, Ponto de máximo $=8,35 ;{ }^{11} \mathrm{Y}=0,522+0,089 \mathrm{x}, \mathrm{R}^{2}=0,98$; ${ }^{12} \mathrm{AGPI}-$ ácidos graxos poliinsaturados; ${ }^{13} \mathrm{AGMI}$ - ácidos graxos monoinsaturados; ${ }^{14} \mathrm{AGS}$ - ácidos graxos saturados; ${ }^{15} \mathrm{n}-6$ - ácidos graxos da série Omega 6; ${ }^{16} \mathrm{n}-3$ - ácidos graxos da série Omega $3 ;{ }^{17} \mathrm{AGPI} / \mathrm{AGS}$ razão entre os ácidos graxos poli-insaturados e os ácidos graxos saturados; ${ }^{18} \mathrm{n}-6 / \mathrm{n}-3$ - razão entre os ácidos graxos da série Omega 6 e Omega $3 ;{ }^{19} \mathrm{CLA}$ - ácido linoléico conjugado.

Fonte: Elaboração dos autores.

Segundo Chilliard et al. (2000), os ácidos graxos poli-insaturados não são sintetizados pelos tecidos dos ruminantes e, portanto, sua concentração no leite dependente da quantidade destes ácidos graxos que chegam ao duodeno provenientes da dieta. A elevação dos AGMI pode esta relacionada ao acréscimo encontrado no vacênico e oleico no presente estudo.

Em contrapartida, a concentração dos ácidos graxos saturados (AGS) decresceu linearmente $(\mathrm{P}<0,05)$, com redução de 0,669 para cada unidade de glicerina de baixa pureza inclusa. Esse efeito ocorreu devido ao aumento no fornecimento da glicerina na dieta, que é uma fonte lipídica rica em ácidos graxos insaturados. Outro motivo que possivelmente pode ter ocorrido é o menor suprimento dos ácidos acético e butírico, produzidos por ação microbiana ruminal, e utilizados na síntese dos ácidos graxos de cadeia curta do leite (JENKINS, 1995).

A concentração dos ácidos graxos da série Omega 6 (n-6) apresentou efeito linear decrescente $(\mathrm{P}<0,05)$, com redução de 0,014 para cada unidade de glicerina acrescentada. Este efeito ocorreu devido à redução observada para as concentrações do ácido 
linoleico $\mathrm{C}_{18: 2 n 6}$ na gordura no leite desta pesquisa. Já para a concentração de Omega 3(n-3), não foi observado efeito $(\mathrm{P}>0,05)$ da inclusão de glicerina sobre os tratamentos, apresentando média de 0,28. Este efeito pode ser justificado pela semelhança observada para as concentrações no ácido linolênico $\mathrm{C}_{\text {18:2n3 }}$ no presente estudo.

A razão AGPI $\mathrm{AGS}^{-1}$ apresentou crescimento linear $(\mathrm{P}<0,05)$, com acréscimo de 0,001 para cada unidade de glicerina inclusa. $\mathrm{O}$ aumento linear na razão $\mathrm{AGPI} \mathrm{AGS}^{-1}$ pode ser explicado pela maior proporção de AGPI na composição da glicerina, à medida que foram inclusos os níveis do coproduto, o que, provavelmente, diminuiu a eficiência do processo de bio-hidrogenação ruminal, gerando um maior escape desses ácidos graxos para absorção intestinal, já que a razão AGPI AGS-1, encontrada no leite de animais ruminantes, está relacionada à bio-hidrogenação dos ácidos graxos insaturados dietéticos, ocorridos no rúmen, capaz de os transformarem em ácidos graxos saturados.

A razão n-6 n-3-1 apresentou efeito quadrático $(\mathrm{P}<0,05)$, com ponto de máximo de 8,35 com a inclusão dos níveis de glicerina. Este efeito pode está associado à alteração observada para n-6 e à semelhança encontrada para os ácidos graxos da serie Omega3, que, provavelmente, contribuiu para essa variação encontrada para a razão n6 $n 3^{-1}$. Apesar da variação observada, os valores encontrados para todos os tratamentos estão acima dos valores recomendados pelo Departamento de Saúde da Inglaterra (HMSO, 1994), para a redução de riscos de câncer e problemas coronarianos, que deve ser inferior a 4 .

Segundo Simopoulos (2002), embora as exigências quantitativas para os ácidos graxos ômega 3 ainda não tenham sido estabelecidas, admite-se que a razão possa variar de 5:1 a 10:1, esses valores corroboram com os valores observados nesta pesquisa.

A concentração do ácido linoleico conjugado (CLA) total apresentou efeito linear crescente
$(\mathrm{P}<0,05)$, com acréscimo de 0,089 para cada unidade de glicerina de baixa pureza acrescentada. Este efeito ocorreu em decorrência do acréscimo encontrado para as concentrações dos isômeros $\mathrm{C}_{18: 2 \text { cis-9 trans-11 }} \mathrm{e}$ $\mathrm{C}_{18: 2 \text { trans-10 cis-12. }}$ Esse resultado é desejável, uma vez que o CLA é um ácido graxo de origem animal com propriedade anticarcinogênica e está relacionado à redução na incidência de doenças cardiovasculares, prevenção e tratamento de tumores (TAPIERO; NGUYEN; COUVREUR, 2002).

\section{Conclusão}

Os teores de ácido linoleico conjugado (CLA) no leite aumentam à medida que os níveis crescentes de glicerina de baixa pureza são incluídos na dieta das vacas, proporcionando, a produção de leite de maior qualidade para o consumo humano. Recomendase a inclusão de glicerina de baixa pureza na dieta de vacas leiteiras até o nível de $20 \%$, com base na matéria seca.

\section{Aprovação do conselho de Ética}

O presente estudo foi aprovado pelo conselho de ética da Universidade Estadual do Sudoeste da Bahia e foi conduzido de acordo com as normas técnicas de biosegurança e ética.

\section{Agradecimentos}

À Universidade Estadual do Sudoeste da Bahia, à Coordenação de Aperfeiçoamento de Pessoal de Nível Superior, pela bolsa concedida ao primeiro autor, ao grupo de pesquisa Produção Animal na Bahia e ao Professor Doutor Fabiano Ferreira da Silva pela orientação.

\section{Referências}

AVILA, C. D.; De PETERS, E. J.; PEREZ-MONTI, H. Influences of saturation ratio of supplemental dietary fat on digestion and milk yield in dairy cows. Journal of Dairy Science, Savoy, v. 80, n. 9, p. 2204-2212, 2000. 
BANNON, C. D.; BREEN, G. J.; CRASKE, J. D.; HAI, N. T.; HARPER, N. L.; O'ROURKE, K. L. Analysis of fattu acid methyl esters with high accuracy and reliability. Journal of Chromatography, Balmain, v. 247, n. 1, p. 6369, 1982.

BAUMAN, D. E.; GRIINARI, J. M. Regulation and nutritional manipulation of milk fat: low-fat milk syndrome. Livestock Production Science, Amsterdam, v. 70, n. 1-2, p. 15-29, 2001.

BEAULIEU, A. D.; DRACKLEY, J. K.; MERCHEN, N. R. Concentrations of conjugated linoleic acid (cis-9, trans-11 octadienoic acid) are not increased in tissue lipids of cattle fed with high concentrate died supplemented with soybean oil. Journal of Animal Science, Champaign, v. 80 , n. 3, p. $847-861,2002$.

BERCHIELLI, T. T.; PIRES, A. V.; OLIVEIRA, S. G. Nutrição de ruminantes. Jaboticabal: Funep, p. 583, 2006.

BERGNER, H.; KIJORA, C.; CERESNAKOVA, Z.; SZAKACS J. In vitro studies on glycerol transformation by rumen microorganisms. Archiv für Tierernährung, Berlim, v. 48, n. 3, p. 245-256, 1995.

CHILLIARD, Y.; BOCQUIER, F. Effects of fat supplementation on milk yield and composition in dairy goats and ewes. In: INTERNATIONAL SYMPOSIUM LA QUALITA NELL PRODUZIONI DEI PICCOLI RUMINANTI, 5., 1993, Varese. Proceedings... Varese: Camera di Commercio Industria Artigianato Agricultura di Varese, p. 61-78, 1993.

CHILLIARD, Y.; FERLAY, A.; MANSBRIDGE, R. M.; DOREAU, M. Ruminant milk fat plasticity: nutritional control of saturated, polyunsaturated, trans and conjugated fatty acids. Annales de Zootechnia, SaintGenès-Champanelle, v. 49, n. 3, p. 181-205, 2000.

COSTA, R. G.; MESQUITA, Í. V. U.; QUEIROGA, R. C. R. E.; MEDEIROS, A. N.; CARVALHO, F. F. R.; BELTRÃO FILHO, E. M. Características químicas e sensoriais do leite de cabras Moxotó alimentadas com silagem de maniçoba. Revista Brasileira de Zootecnia, Viçosa, MG, v. 37, n. 4, p. 694-702, 2008.

DAVIS, S. R.; COLLIER, R. J. Mammary blood flow and regulation of substrate supply for milk synthesis. Journal of Dairy Science, Savoy, v. 68, n. 4, p. 1041-1058, 1985.

DEMEYER, D.; DOREAU, M. Targets and procedures for altering ruminant meat and milk lipids. Proceedings of the Nutrition Society, Ghent, v. 58, n. 3, p. 593-607, 1999.

DEPARTMENT OF HEALTH - HMSO. Nutritional aspects of cardiovascular disease HMSO. London, p. 3746, 1994. (Report on Health and Social Subjects, 46).
EIFERT, E. C.; LANA, R. P.; LANNA, D. P. D.; LEOPOLDINO, W. M.; ARCURI, P. B.; LEÃO, M. I.; COTA, M. R.; VALADARES FILHO, S. C. Perfil de ácidos graxos do leite de vacas alimentadas com óleo de soja e monensina no início da lactação. Revista Brasileira de Zootecnia, Viçosa, MG, v. 35, n. 1, p. 219-228, 2006.

FERNANDES, A. R. M.; SAMPAIO, A. A. M.; HENRIQUE, W.; OLIVEIRA, E. A.; OLIVEIRA, R. V.; LEONEL, F. R. Composição em ácidos graxos e qualidade da carne de tourinhos Nelore e Canchim alimentados com dietas à base de cana-de-açúcar e dois níveis de concentrado. Revista Brasileira de Zootecnia, Viçosa, MG, v. 38, n. 2, p. 328-337, 2009.

FOLCH, J.; LEES, M.; STANLEY, G. H. S. A simple method for the isolation and purification of total lipids from animal tissues. The Journal of Biological Chemistry, Maryland, v. 226, n. 1, p. 497-509, 1957.

FOX, P. F.; MCSWEENEY, P. L. H. Milk lipids. In: FOX, P. F.; MCSWEENEY, P. L. H. (Ed.). Dairy chemistry and biochemistry. London, UK: Blackie Academic \& Professional, 1998 .p. 67-145.

GRUMMER, R. R. Effect of feed on the composition of milk fat. Journal of Dairy Science, Savoy, v. 74, n. 9, p. 3244-3257, 1991.

INTERNATIONAL ORGANIZATION FOR STANDARDIZATION - ISO. Method ISO 5509. Geneve: ISO, 1978. 6 p.

JENKINS, T. C. Lipid metabolism in the rumen. Journal of Dairy Science, Savoy, v. 76, n. 12, p. 3851-3863, 1995.

MADSEN, T. G.; NIELSEN, L.; NIELSEN, M. O. Mammary nutrient uptake in response to dietary supplementation of rumen protected lysine and methionine in late and early lactating dairy goats. Small Ruminant Research, Amsterdam, v. 56, n. 1-3, p. 151164, 2004.

MALAU-ADULI,A.E. O.; SIEBERT, B. D.; BOTTEMA, C. D. K. A. Comparison of the fatty acid composition of tryacilglycerols in adipose tissue from Limousin and Jersey cattle. Australian Journal of Agriculture Research, Victoria, v. 48, n. 5, p. 715-722, 1997.

MASSART- LËEN, A. M.; ROETS, E.; PEETERS, G.; VERBEKE, R. Propionate for fatty acid synthesis by mammary gland of the lactanting goat. Journal of Dairy Science, Savoy, v. 66, n. 7, p. 1445-1454, 1983.

MCGUIRE, M. A.; MCGUIRE, M. K.; GUY, M. A.; SANCHEZ, W. K.; SHULTZ, T. D.; HARISON, L. Y.; BAUMAN, D. E.; GRIINARI, J. M. Effect of dietary lipid concentration on content of conjugated linoleic acid (CLA) in milk from dairy cattle. Journal of Animal Science, Champaign, v. 74, p. 266, 1996. Supplement 1. 
NATIONAL RESEARCH COUNCIL - NRC. Nutrient requirements of dairy cattle. 7. ed. Washington: Ed. National Academy Press, 2001. 387 p.

OLIVEIRA, M. A.; REIS, R. B.; LADEIRA, M. M. Produção e composição do leite de vacas alimentadas com dietas com diferentes proporções de forragem e teores de lipídeos. Arquivo Brasileiro de Medicina Veterinária e Zootecnia, Belo Horizonte, v. 59, n. 3, p. 759-766, 2007.

PADILHA, P. C.; PINHEIRO, R. L. O papel dos alimentos funcionais na prevenção e controle do câncer de mama. Revista Brasileira de Cancerologia, Rio de Janeiro, v. 50, n. 3, p. 251-260, 2004.

PALMQUIST, D. L.; MATTOS, W. R. S. Metabolismo de lipídios. In: BERCHIELLI, T. T.; VAZ PIRES, A.; OLIVEIRA, S. G. de. (Ed.). Nutrição de ruminantes. Jaboticabal: FUNEP, 2006. p. 287-310.

PARODI, P. W. Conjugated linoleic acid and other anticarcinogenic agents of bovine milk fat. Journal of Dairy Science, Savoy, v. 82, n. 6, p. 1339-1349, 1999.

PIPEROVA, L. S.; TETER, B. B.; BRUCKENTAL, I. Mammary lipogenic enzyme activity, trans fatty acids and conjugated linoleic acids are altered in lactating dairy cows fed a milk fat depressing diet. Journal of Nutrition, Bethesda, v. 130, n. 12, p. 2568-2574, 2000.

PREGNOLATO, W.; PREGNOLATO, N. P. Métodos químicos e físicos para análise de alimentos. In: PREGNOLATO, W. Normas analíticas do Instituto Adolfo Lutz. 3. ed. São Paulo: Instituto Adolfo Lutz, 1985. v. 1, p. 13-50.

REVENEAU, C. Dietary source and availibility of fatty acids to manipulate ruminal protozoa, metabolism of fat, and milk fatty acid profile in lactating dairy cows. 2008. Thesis (Doctor in Physiology) - Ohio State University, Columbus.

SISTEMA PARA ANÁLISES ESTATÍSTICAS - SAEG. Sistema para análises estatísticas, versão 9. 1. Viçosa: UFV, 2007.
SANTOS, F. L.; SILVA, M. T. C.; LANA, R. P.; BRANDÃO, S. C. C.; VARGAS, L. H.; ABREU, L. R. Efeito da suplementação de lipídios na ração sobre a produção de ácido linoleico conjugado (CLA) e a Composição da Gordura do Leite de Vacas. Revista Brasileira de Zootecnia, Viçosa, MG, v. 30, n. 6, p. 19311938, 2001.

SANTOS, J. F.; DIAS JÚNIOR, G. S.; BITENCOURT, L. L.; LOPES, N. M.; SIÉCOLA JÚNIOR, S.; SILVA, J. R. M.; PEREIRA, R. A. N.; PEREIRA, M. N. Resposta de vacas leiteiras à substituição parcial de farelo de soja por ureia encapsulada. Arquivo Brasileiro de Medicina Veterinária e Zootecnia, Belo Horizonte, v. 63, n. 2, p. 423-432, 2011.

SILVA, D. J.; QUEIROZ, A. C. Análise de alimentos: métodos químicos e biológicos. 3. ed. Viçosa, MG: Editora UFV, 2002. $235 \mathrm{p}$.

SIMIONATO, J. I.; GARCIA, J. C.; DOS SANTOS, G. T.; OLIVEIRA, C. C.; VISENTAINER, J. V.; SOUZA, N. E. Validation of the determination of fatty acids in milk by gas chromatography. Journal Brazilian Chemical Society, São Paulo, v. 21, n. 3, p. 520-524, 2010.

SIMOPOULOS, A. P. The importance of the ratio of omega-6/omega-3 essential fatty acids. Biomedicine \& Pharmacotherapy, Washington, v. 56, n. 8, p. 365-379, 2002.

TAPIERO, H.; NGUYEN, B.; COUVREUR, P. Polyunsaturated fatty acids (PUFA) and eicosanoids in human health and pathologies. Biomedicine \& Pharmacotherapy, Chatenay Malabry, v. 56, n. 5, p. 215 222, 2002.

VASCONCELOS DE SÁ, L. R.; CAMMAROTA, M. C.; FERREIRA-LEITÃO, V. S. Produção de hidrogênio via fermentação anaeróbia - aspectos gerais e possibilidade de utilização de resíduos agroindustriais brasileiros. Química Nova, São Paulo, v. 37, n. 5, p. 857-867, 2014.

VISENTAINER, J. V.; FRANCO, M. R. B. Ácidos graxos em óleos e gorduras: identificação e quantificação. São Paulo: Varela, 2006. 120 p. 